\title{
Informational Externalities and Welfare-Reducing Speculation
}

\section{Citation}

Stein, Jeremy C. 1987. Informational externalities and welfare-reducing speculation. Journal of Political Economy 95(6): 1123-1145.

\section{Published Version}

http://dx.doi.org/10.1086/261508

\section{Permanent link}

http://nrs.harvard.edu/urn-3:HUL.InstRepos:3660740

\section{Terms of Use}

This article was downloaded from Harvard University's DASH repository, and is made available under the terms and conditions applicable to Other Posted Material, as set forth at http:// nrs.harvard.edu/urn-3:HUL.InstRepos:dash.current.terms-of-use\#LAA

\section{Share Your Story}

The Harvard community has made this article openly available.

Please share how this access benefits you. Submit a story.

Accessibility 


\section{CHICAgo journals}

Informational Externalities and Welfare-Reducing Speculation

Author(s): Jeremy C. Stein

Source: The Journal of Political Economy, Vol. 95, No. 6 (Dec., 1987), pp. 1123-1145

Published by: The University of Chicago Press

Stable URL: http://www.jstor.org/stable/1831115

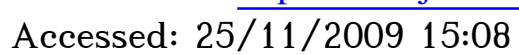

Your use of the JSTOR archive indicates your acceptance of JSTOR's Terms and Conditions of Use, available at http://www.jstor.org/page/info/about/policies/terms.jsp. JSTOR's Terms and Conditions of Use provides, in part, that unless you have obtained prior permission, you may not download an entire issue of a journal or multiple copies of articles, and you may use content in the JSTOR archive only for your personal, non-commercial use.

Please contact the publisher regarding any further use of this work. Publisher contact information may be obtained at http://www.jstor.org/action/showPublisher?publisherCode=ucpress.

Each copy of any part of a JSTOR transmission must contain the same copyright notice that appears on the screen or printed page of such transmission.

JSTOR is a not-for-profit service that helps scholars, researchers, and students discover, use, and build upon a wide range of content in a trusted digital archive. We use information technology and tools to increase productivity and facilitate new forms of scholarship. For more information about JSTOR, please contact support@jstor.org.

The University of Chicago Press is collaborating with JSTOR to digitize, preserve and extend access to The Journal of Political Economy. 


\section{Informational Externalities and \\ Welfare-reducing Speculation}

\section{Jeremy C. Stein}

Harvard University

Introducing more speculators into the market for a given commodity leads to improved risk sharing but can also change the informational content of prices. This inflicts an externality on those traders already in the market, whose ability to make inferences based on current prices will be affected. In some cases, the externality is negative: the entry of new speculators lowers the informativeness of the price to existing traders. The net result can be one of price destabilization and welfare reduction. This is true even when all agents are rational, risk-averse, competitors who make the best possible use of their available information.

\section{Introduction}

For years, economists have debated the merits of speculative behavior. Milton Friedman set the tone for the debate when he claimed: "People who argue that speculation can be destabilizing seldom realize that this is largely equivalent to saying that speculators lose money, since speculation can be destabilizing in general only if speculators sell when the currency is low in price and buy when it is high" (1953, p. 175). In other words, rational speculators should exert a stabilizing influence by bidding up low prices and selling off at high prices.

Financial support from the National Science Foundation and the Board of Governors of the Federal Reserve is gratefully acknowledged. Thanks also to Arnold Kling, Ed Green, Stanley Fischer, Oliver Hart, Jean Tirole, Bob Gibbons, the referee, and seminar participants at the Board of Governors, MIT, and Harvard for their comments. 
Friedman's claim drew a flurry of counterexamples. The more recent of these, such as Salant (1984) and Hart and Kreps (1986), demonstrate that, even in a general equilibrium framework with optimizing speculators, prices can be destabilized. However, these examples also point up a serious flaw in the whole destabilization literature: the fact that, for arbitrary preferences, price stability need not correspond closely to any measure of consumer or social welfare. Indeed, the examples of Hart and Kreps and Salant rely on consumer preferences that change over time, so speculation that destabilizes prices actually improves consumer welfare. This is an expected result since both papers compare a regime with speculation with a regime with no speculation. As Salant notes, a simple gains-from-trade argument ensures that consumers will always be better off when they are allowed to trade with speculators than when they do not have this option.

Unfortunately, the question whether some speculation is better than none is probably not a very relevant one. In terms of real-world policy-making, it seems more interesting to ask: "Is more speculation better than less?" Gains-from-trade arguments offer no help here. Yet one of the most important implications of the stabilizationdestabilization debate concerns the desirability of opening futures or options markets. Such markets can be thought of as a conduit through which a greater number of speculators can flow into an already existing spot market. Regulators have frequently expressed concern that futures and options markets can be price destabilizing and welfare reducing, and they have considered measures to address these problems. Theoretical economists, on the other hand, have tended to follow the spirit of Friedman. Both Danthine (1978) and Turnovsky (1983) present models in which futures markets are seen as a stabilizing influence.

This paper demonstrates how introducing a new group of speculators into the spot market for a commodity (corresponding to the opening of a futures or options market) can destabilize prices. The model does not rely on any shifts in consumer preferences. Consumer utility functions are very simple and time symmetric. Consequently, price stability and welfare are closely related: in the examples to be seen here, stabler prices will be associated with higher levels of welfare, and price destabilization can be shown to be welfare reducing.

The model presented here focuses on two aspects of speculative behavior, risk sharing and information transmission. The risksharing benefit of increased speculation is well recognized. All else being equal, the introduction of new agents into a system lowers the aggregate risk aversion, thereby strengthening the arbitrage forces that lead to the stabilization of prices. For example, the opening of a futures market allows risk-averse producers and inventory holders to 
hedge their production and storage decisions by locking in a sales price with short futures contracts. This hedging (which amounts to unloading some of their risk onto the new pool of people that the futures market brings into the system) enables them to respond more strongly to price signals, thereby reducing price variability.

A less frequently noted aspect of the speculation problem concerns the information that is communicated by market prices. In spite of the rapid development of a vast literature on information in prices (Grossman [1976, 1977, 1978], Grossman and Stiglitz [1980], and Hellwig [1980] are a few examples), even the more recent papers on the intertemporal price stability properties of speculation (i.e., Hart and Kreps, Salant, and Turnovsky) have tended to ignore the issue of heterogeneous information among market participants. ${ }^{1}$

In the model of this paper, information is of crucial importance. In addition to providing increased risk sharing, new speculators with private information can change the informational content of prices. In some cases, this inflicts a negative externality on those people already in the market: their ability to make inferences from prices is impaired. If this "misinformation" effect is strong enough relative to the need for additional risk sharing, welfare losses can result. It should be emphasized that the misinformation does not arise from any irrationality on the part of the new speculators. They are rational profit-maximizing competitors who make the best possible use of their available information.

For concreteness, the paper discusses increased speculation in the context of a particular example: the opening of a futures market for a perfectly storable commodity. This example encompasses a variety of markets in which the desirability of futures trading has been debated: those for certain agricultural products, as well as for stocks, bonds, currencies, gold, and silver. Furthermore, it will be argued that the welfare effects of opening options markets can be analyzed in the same framework.

The paper is organized as follows. Section II details the basic structure and assumptions of the model. Included in this section is an analysis of the welfare properties of speculative regimes, as well as a formal demonstration of the fact that opening a futures market is exactly equivalent to allowing more speculators to participate in the

\footnotetext{
' One exception is Danthine (1978), where futures markets are seen as stabilizing because they allow producers to learn more about the state of the world (by looking at the futures price) than they otherwise would. However, Danthine's model is somewhat "rigged" in favor of stability since he assumes that futures market participants are strictly better informed than the producers of the commodity. The motivation behind such an assumption is unclear: as will be shown here, it is not needed to ensure that the futures market players earn a profit and hence stay in business.
} 
spot market. Section III examines the price stability and welfare effects of futures market trading under three different sets of assumptions concerning the distribution of information in the economy. Section IV summarizes and offers some conclusions.

\section{The Model}

\section{A. Consumers}

In this two-period model, consumers are assumed to derive utility from two sources: consumption of both the commodity in question (call it wheat) and a "background" or numeraire good, which can be taken to represent all other goods. If we denote first-period consumption of wheat by $C_{1}$, second-period wheat consumption by $C_{2}$, and total two-period consumption of the numeraire good by $N$, aggregate consumer utility is assumed to be given by

$$
U\left(C_{1}, C_{2}, N\right)=D C_{1}-\frac{C_{1}^{2}}{2}+D C_{2}-\frac{C_{2}^{2}}{2}+N .
$$

That is, utility is concave in $C_{1}$ and $C_{2}$ but linear in the numeraire good. This Marshallian utility function is popular in the literature on speculation, mostly because it leads to the following simple demand curves (see the Appendix for all derivations not given in the text):

$$
\begin{aligned}
& C_{1}=D-P_{1}, \\
& C_{2}=D-P_{2} .
\end{aligned}
$$

From now on, $D$ will be taken to be equal to zero. This normalization does not affect the analysis at all and is just used to simplify the notation that is to follow. ${ }^{2}$

Consumers receive a stochastic endowment of wheat in each of the two periods, which they are unable to store directly. The shocks that buffet the market are of two types, transitory and permanent. In the first period, there is a total supply shock of $A+X$, where $A$ is the permanent component (it will be present in the second period as well) and $X$ is the first-period transitory component. In the second period, the total shock is $A+Y$ : the permanent $A$ shock plus the new secondperiod transitory shock, given by $Y$. The three shocks are assumed to be independent of each other, normally distributed, with zero mean and variances of $v_{a}, v_{x}$, and $v_{y}$, respectively. One might think of the transitory shocks as being caused by passing disruptions such as bad

2 The interpretation is that "consumption demand" really refers to "deviation from mean consumption demand," and "price" really refers to "deviation from mean price." Working with "demeaned" variables results in a considerable economy of notation. 
weather or soil conditions, while the permanent shocks come from more lasting changes such as decreases in the number of acres being farmed. Given the assumptions on supply, as well as the zero intercept demand schedule, it is easy to calculate market-clearing prices. If the total inventory held in period 1 is $I$ and this inventory must be unloaded in period 2 , prices are given by

$$
\begin{aligned}
& P_{1}=-A-X+I, \\
& P_{2}=-A-Y-I .
\end{aligned}
$$

As these equations show, the objective in specifying the stochastic structure above is to inject the potential for confusion among imperfectly informed speculators who try to make inferences from the firstperiod price. There is no point in holding inventories if prices are low because of an $A$ shock, because that shock will persist through the next period, keeping prices low and preventing speculative gain. However, if prices are low because of a temporary $X$ disturbance, then it does make sense to speculate, because that shock will be gone next period and prices will tend to rise. In what follows, varying assumptions will be made concerning the observability of the shocks: one group will be able to observe the transitory shock (they are farmers who are experts on soil conditions, e.g.) while another group may know something about the permanent shock (their stockbroker has some statistics on the acreage being devoted to wheat farming).

\section{B. Speculative Demand for Inventories and Futures Contracts}

Aside from the consumers, there are two other groups in the economy. They consist of $n_{1}$ "spot traders" and $n_{2}$ "secondary traders." Spot traders are assumed to be able to store inventories costlessly. ${ }^{3}$ Secondary traders, on the other hand, do not have inventory capability. The only way that they can participate in this economy is through the use of futures contracts. If the commodity in question is wheat, we can think of the spot traders as being the only ones who own grain silos. In a financial setting, the spot traders can represent the large institutions that can easily go long and short in cash market instruments, while the secondary traders are the smaller investors that can take only certain positions-particularly short ones or highly leveraged long ones-through the use of financial futures.

Thus in a world without futures markets, the only players are the spot traders. Introducing futures markets includes the secondary

\footnotetext{
${ }^{3}$ Linear carrying costs would change nothing essential.
} 
traders in the activity. Both types of agents are assumed to have the same constant absolute risk aversion utility functions: $U(\Pi)=-e^{-B \pi}$, where $B$ is the coefficient of risk aversion and $\Pi$ is profits. ${ }^{4}$ Consumers are assumed not to trade in the futures market. This may appear restrictive since their utility is linear in the numeraire, which would lead them to behave as risk-neutral speculators if they could trade. However, we will always consider those cases in which the number of secondary traders, $n_{2}$, goes to infinity, thereby making that group behave in a risk-neutral fashion. If we just assume that the information set of the consumers is the same as that of the secondary traders, there is no loss of generality in ignoring the speculative demands of the consumers. ${ }^{5}$

The spot traders' information set will be denoted by $\Omega_{1}$, and for shorthand, $E_{1}()$ will stand for $E\left(/ \Omega_{1}\right)$ and $V_{1}()$ will stand for $\operatorname{var}\left(/ \Omega_{1}\right)$. Similar notation applies for the secondary traders' information set $\Omega_{2}$ and their conditional means and variances. It is assumed that, in addition to the market price, spot traders are able to observe the transitory shock $X$. Secondary traders, on the other hand, have some information about the permanent shock $A$, although this information is imperfect. Specifically, secondary traders observe $Z=$ $A+W$, where $W$ is another independent mean zero normal with variance $v_{W}$.

It is easy to show that, in a world without futures, the spot traders' demand for inventories in the first period is given by

$$
I=k_{1}\left(E_{1} P_{2}-P_{1}\right),
$$

where $k_{1}=n_{1} /\left[B V_{1}\left(P_{2}\right)\right]$ and $P_{1}$ and $P_{2}$ are the spot prices in the first and second periods, respectively.

Once futures are introduced, costless storage and a zero interest rate imply that the futures price $P_{f}$ must equal the current spot price $P_{1} \cdot{ }^{6}$ Hence in equilibrium, the futures price is informationally redundant: it does not convey any additional information above and beyond

\footnotetext{
${ }^{4}$ Note that speculators care only about consuming the numeraire good; unlike consumers, they want wheat only for the possible trading gains it may net them.

${ }^{5}$ This claim actually involves somewhat more than meets the eye. If consumers were allowed to participate, we would have to account for the fact that, in addition to observing the price and any private signal, they can also observe their own endowment. In order to make the results of the paper apply in this more complex case, the dimensionality of the model would have to be raised so that consumers with three sources of data $\left(P_{1}\right.$, a noisy private signal, and their initial endowment) could still face some uncertainty. For example, we could have first-period supply equal $A+B+X$ and second-period supply equal $A+(B / 2)+Y$.

${ }^{6}$ This is a consequence of inventory arbitrage. If, e.g., we had $P_{1}<P_{f}$, spot traders could buy wheat, store it, and deliver into a short futures position for a risk-free profit.
} 
that conveyed by the spot price. ${ }^{7}$ Still, one should not take this to mean that futures markets have no informational role. The introduction of a futures market can change the equilibrium spot pricing function so that spot prices will reflect information different from that in the absence of a futures market.

Spot traders' demand for futures can be shown to be

$$
F_{1}=-I_{f}+k_{1}\left(E_{1} P_{2}-P_{f}\right) \text {, }
$$

where $I_{f}$ is the inventory the spot traders hold when they are allowed to participate in the futures market. Equation (7) is a separation result: one can think of spot traders as hedging their inventories perfectly with the $-I_{f}$ contracts and then adding additional contracts to the extent that they want to take a risky position and expect prices to move one way or the other.

Secondary traders, on the other hand, have no inventories to hedge. Their demand for futures contracts is given by

$$
F_{2}=k_{2}\left(E_{2} P_{2}-P_{f}\right),
$$

where $k_{2}=n_{2} /\left[B V_{2}\left(P_{2}\right)\right]$. Equations (7) and (8) allow us to state the following proposition.

Proposition 1. In the presence of a futures market, inventories held by spot traders are the same as those that would be held by both groups combined in a spot market economy in which both had storage capability; that is, $I_{f}=k_{1}\left(E_{1} P_{2}-P_{1}\right)+k_{2}\left(E_{2} P_{2}-P_{1}\right)$.

The proposition follows immediately from the futures marketclearing condition that $F_{1}+F_{2}=0$, combined with the fact that $P_{f}=$ $P_{1}$. The intuition is that even though secondary traders are not allowed to buy inventories directly, with costless storage they pass their would-be inventory demands directly through to spot traders via the futures market. For example, suppose that secondary traders are very optimistic about next period's price. If they could store inventories, they would do that. Instead they try to buy futures contracts. Even if the spot traders do not share their optimism, they will sell them the contracts. Having sold the futures, the spot traders then store extra inventories to put in place a perfect, costless hedge. They are at no risk since the extra inventory can be delivered into the short futures position. In other words, high futures demand by secondary traders induces the spot traders to buy the inventories that the secondary traders themselves would have bought if they had direct access to the spot market.

\footnotetext{
${ }^{7}$ This is in contrast to Grossman (1977) and Danthine (1978), where convex storage costs break the equality between spot and futures prices.
} 
The proposition is useful because it allows a compact mathematical treatment of the addition of a futures market. There is no need to explicitly keep track of futures prices or holdings; one can proceed simply by pretending that the inventory spot market has been opened to the secondary traders. ${ }^{8}$

A similar logic would apply to the opening of an options market. Suppose that there are two groups in the economy and that the first can borrow and lend costlessly while the second faces credit constraints. What happens if traders in the second group receive some very bullish information that makes them wish to take a large position in the asset in question? Without an options market, they will be unable to borrow enough to take the position they want. With an options market, however, they can control many more shares by buying calls. The first group can sell them these calls and then execute a costless hedge à la Black and Scholes (1973) by buying shares and borrowing in the right proportions. Once again, the secondary market allows asset demands to be transmitted through to the "big players" who can deal costlessly in the spot market. ${ }^{9}$

\section{Welfare Considerations}

Given the consumer utility function above, we can see that when inventories are carried from one period to the next so as to stabilize prices (which is the same as stabilizing consumption since $P_{2}-P_{1}=$ $C_{1}-C_{2}$ ), there are two effects on consumer welfare. First, the concavity and time symmetry of the function in $C_{1}$ and $C_{2}$ imply a benefit to

${ }^{8} \mathrm{~A}$ referee has pointed out that opening a futures market is not exactly like adding more spot traders since in the former case the existing spot traders are selling futures contracts to and essentially performing storage for the secondary traders and, hence, may be learning something about their private information (which clearly would not be true if the secondary traders could buy inventories on their own). However, it turns out that no new information is communicated to spot traders, either by their own futures positions or by aggregate open interest data. This is because individual futures positions are indeterminate; it is not true that each spot trader will hold $1 / n_{1}$ of the futures positions and corresponding extra inventory and hence can deduce total extra inventory due to secondary traders. All that is determined is each spot trader's net unhedged position. Open interest is similarly meaningless: even if secondary trader net demand is zero, it is possible to have open interest in futures since some spot traders can be long the contract and have smaller inventory holdings, while others are short and store more.

${ }^{9}$ There seems to be some confusion among finance theorists on this point. It is often claimed that "since options are redundant, they do not change the equilibrium asset prices." This would hold true only if everybody in the economy could borrow and lend costlessly so that introducing options changed nobody's opportunity set. But if this were the case, why would anybody trade in options at all? The Black-Scholes formula still holds when only some agents can borrow and lend costlessly, although asset prices cannot strictly be taken as exogenous: opening an options market indirectly changes asset demands and, hence, their price processes. 
stability since, for a given consumption of the numeraire good $N$, consumers would prefer to consume their total wheat allotment as smoothly as possible: they would like $C_{1}$ as close to $C_{2}$ as they can have it. Second, inventory activity affects the profits of the speculative traders, given by $\Pi=I\left(P_{2}-P_{1}\right)$, with any such profits entailing a transfer of the numeraire good $N$ from the consumers to the speculators. This profit effect can run either way: profits first rise as inventory activity rises from zero to a positive level but then fall as prices are forced to equality. Taking the two effects together, we can write expected consumer surplus as

$$
U^{C}=E\left(-\frac{C_{1}^{2}}{2}-\frac{C_{1}^{2}}{2}-\Pi\right),
$$

where $U^{C}$ is expected consumer welfare and $\Pi$ is the total profit earned by the speculative traders. From the point of view of consumers with a fixed endowment of wheat, the ideal situation is one in which $P_{2}=P_{1}$. Not only is their wheat consumption perfectly smoothed, but their consumption of the numeraire good is maximized since speculative profits are zero.

It is also useful to examine social welfare, which entails adding some measure of speculators' expected utilities to those of the consumers. Given the normality assumptions, each speculator's utility function is equivalent to

$$
U^{i}=E\left(\Pi_{i}\right)-\frac{B}{2} \operatorname{var}\left(\Pi_{i}\right),
$$

where $U^{i}$ and $\Pi_{i}$ are the utility and profit of the $i$ th speculator. This is perhaps the most natural utility measure to use in constructing the social welfare function since it leads to an equal weighting of all groups' expected consumption of the numeraire good. ${ }^{10}$ When we sum over all the speculators in both groups, expected social welfare is given by

$$
U^{s}=E\left[-\frac{C_{1}^{2}}{2}-\frac{C_{2}^{2}}{2}-\frac{B}{2 n_{1}} V_{1}\left(\Pi_{1}\right)-\frac{B}{2 n_{2}} V_{2}\left(\Pi_{2}\right)\right],
$$

where $\Pi_{1}$ and $\Pi_{2}$ are the total profits of the first and second groups of traders. The expectation of total speculative profits does not appear in the expression because such profits just represent a transfer of the numeraire good from consumers to traders, which has no net effect on social welfare. ${ }^{11}$

${ }^{10}$ This weighting is not, however, crucial to any of the main results obtained here.

" For a more detailed discussion of the welfare benefits of price stability, see Samuelson (1972). 


\section{Price Variability under Different Informational Scenarios}

In this section, we examine the effects on price variability and welfare of opening a futures market. Three different assumptions are made concerning the accuracy of secondary traders' private information. In subsection $A$, their information is perfect: their observation error has variance $v_{W}=0$ so that they know the $A$ shock exactly. Subsection $B$ considers the opposite extreme where $v_{W}$ is infinite so that secondary traders effectively have no information on $A$ and must use market prices as their only data. Finally, subsection $C$ takes up the more general case in which $v_{W}$ is neither zero nor infinite.

In each case, the method of analysis is essentially the same. First, a rational expectations equilibrium (REE) pricing function for $P_{1}$ is found in terms of the primitive random variables. With the equilibrium $P_{1}$ in hand, it is then an easy task to compute $\left(P_{2}-P_{1}\right)$ and find its variance. It is also straightforward to evaluate the consumer and social welfare measures given by (9) and (11).

\section{A. Secondary Traders Observe A Exactly}

This is the simplest of the three cases. The first-period price will reflect both $X$ and $A$. Since spot traders know $X$, they can infer $A$ exactly by looking at the market price $P_{1}$. Similarly, secondary traders who know $A$ can infer $X$ exactly from the price. Thus this case behaves exactly as if both $X$ and $A$ were directly observed by everyone. The only uncertainty remaining is the second-period transitory shock $Y$ : as a result of this residual risk, inventory demand is still downward sloping with respect to $P_{1} \cdot{ }^{12}$

First, we can derive the equilibrium without futures markets, with only spot traders participating. Assume that the first-period price is given by

$$
P_{1}=\alpha A+\beta X,
$$

with $\alpha$ and $\beta$ undetermined. Using (4) and (5), we can find

$$
\begin{gathered}
I=(\alpha+1) A+(\beta+1) X, \\
P_{2}-P_{1}=-(2 \alpha+2) A-(2 \beta+1) X-Y .
\end{gathered}
$$

Given the information structure posited, spot traders can predict the $A$ and $X$ components of $\left(P_{2}-P_{1}\right)$ perfectly. Only $Y$ is unknown.

\footnotetext{
${ }^{12}$ Nothing is changed if both groups observe $A$ or both observe $X$.
} 
Therefore,

$$
\begin{gathered}
E_{1}\left(P_{2}-P_{1}\right)=-(2 \alpha+2) A-(2 \beta+1) X, \\
V_{1}\left(P_{2}\right)=v_{y} \quad \text { so that } k_{1}=\frac{n_{1}}{B v_{y}} .
\end{gathered}
$$

We can solve for $\alpha$ and $\beta$ by setting the inventory in (13) equal to inventory demand, which is $k_{1}$ times the expected price change given in (15). This procedure yields the following REE solution:

$$
\begin{aligned}
\alpha & =-1, \beta=-\frac{1+k_{1}}{1+2 k_{1}} \text { or } \\
P_{1} & =-A-\frac{X\left(1+k_{1}\right)}{1+2 k_{1}} .
\end{aligned}
$$

This implies

$$
\begin{gathered}
P_{2}-P_{1}=-Y+\frac{X}{1+2 k_{1}}, \\
\operatorname{var}\left(P_{2}-P_{1}\right)=v_{y}+\frac{v_{x}}{\left(1+2 k_{1}\right)^{2}} .
\end{gathered}
$$

From (19), it is clear that speculative behavior is more stabilizing as (1) the number of spot traders, $n_{1}$, increases, (2) the risk aversion $B$ decreases, or (3) the second-period transitory shock $Y$ becomes less variable. All three of these effects serve to increase $k_{1}$, in which price variability is monotonically declining. It is also easy to check (see the Appendix for details) that both consumer and social welfare are monotonically increasing in $k_{1}$ : when $k_{1}$ goes to infinity, not only are prices and consumption as well smoothed as possible, but expected speculative profits are forced to zero, as are the variance terms in (11).

Adding a futures market in this case is trivial. Since secondary traders have exactly the same information as spot traders, all a futures market does is shift the inventory demand function by a factor of $\left(n_{1}\right.$ $\left.+n_{2}\right) / n_{1}$. Equations (17)-(19) are still valid, except that $\left(k_{1}+k_{2}\right)$ replaces $k_{1}$ everywhere, with $k_{2}$ given by $n_{2} / B v_{y}$.

According to the logic above, a futures market is therefore stabilizing and welfare improving. In this case, the addition of speculators has no informational effect at all. It just raises the number of perfectly informed participants in the market. Consequently, we are left with only the beneficial effect of pure risk sharing. As the number of secondary traders gets very large, all instability due to $A$ and $X$ is arbitraged away, and we approach a point where $\operatorname{var}\left(P_{2}-P_{1}\right)=v_{y}$. In this best possible case, $\alpha=-1$ and $\beta=-1 / 2$ : the price reflects the 
permanent shock fully but reflects only half of the transient shock. This corresponds to an inventory scheme in which half of any transient supply shock is stored until the next period but permanent shocks have no effect on storage decisions.

\section{B. Secondary Traders Have No Information on A}

We now consider the case in which secondary traders, having no private information, must rely solely on market prices to make their judgments concerning $A$ and $X$. Clearly, this one source of data is insufficient to allow them to disentangle the two shocks perfectly. The best that they can do in formulating their inventory demands is to use an optimal statistical predictor of the form ${ }^{13}$

$$
\begin{aligned}
E\left(P_{2}-P_{1}\right) / P_{1} & =\frac{P_{1} \operatorname{cov}\left[\left(P_{2}-P_{1}\right), P_{1}\right]}{\operatorname{var}\left(P_{1}\right)} \\
& =\frac{(\alpha A+\beta X)\left[-\alpha(2 \alpha+2) v_{a}-\beta(2 \beta+1) v_{x}\right]}{\alpha^{2} v_{a}+\beta^{2} v_{x}} .
\end{aligned}
$$

Since spot traders know strictly more than secondary traders, they can deduce the secondary traders' inventory demand exactly. (This just reflects the property of the law of iterated expectations that $E_{1} E_{2} P_{2}=E_{2} P_{2}$, given the current setup.) Since spot traders know secondary trader inventory demand as well as the $X$ shock, they can use the price to infer the unobservable $A$ shock perfectly. Thus spot traders are in effect perfectly informed, as in the first scenario.

In the absence of futures markets, the spot market equilibrium is exactly that described in subsection $A$ for the perfectly informed spot traders. Once a futures market is added, we need to find another REE pricing function. The method of solution is the same as before, although it becomes more complicated here. Recall that inventory demand in this case will be given by

$$
I=k_{1} E_{1}\left(P_{2}-P_{1}\right)+k_{2} E_{2}\left(P_{2}-P_{1}\right) .
$$

Group 1's expectation of the price change is given in equation (15). It forms its expectations based on perfect information as to $A$ and $X$. Group 2's expectation of the price change is given by (20), the optimal forecast for someone who observes only the current price. To find the REE, plug these expectations into (21) and set this inventory demand equal to the actual inventory given by (13).

\footnotetext{
${ }^{13}$ Note that this "regression" equation has no constant term since we are working with deviations from means.
} 
The solution to the problem is given by

$$
\alpha=-\frac{d v_{a}}{v_{a}+\left(v_{x} f^{2} / e^{2}\right)}-e ; \beta=\frac{\alpha\left(1+k_{1}\right)}{1+2 k_{1}},
$$

where the following new variables have been defined:

$$
\begin{aligned}
& g=1+3 k_{1}+2 k_{1}^{2}+2 k_{2}\left(1+k_{1}\right), \\
& d=\frac{k_{2}}{g}, \\
& e=\frac{\left(1+k_{1}+k_{2}\right)\left(1+2 k_{1}\right)}{g}, \\
& f=-\frac{\left(1+k_{1}+k_{2}\right)\left(1+k_{1}\right)}{g} .
\end{aligned}
$$

In contrast to the previous example, we do not have a strictly reduced form because of the endogeneity of $k_{2}$. However, it is possible to show that $k_{2}$ does not depend directly on $\alpha$ or $\beta$ so that simultaneity and existence problems are avoided. ${ }^{14}$ One thing that $k_{2}$ does depend on is $k_{1}$. The introduction of more spot traders makes it easier for secondary traders to make inferences from the price, thus lowering $V_{2}\left(P_{2}\right)$ and raising $k_{2}$. (See the Appendix for a demonstration of this fact.)

With respect to price variability, it can be shown that an increase in the number of either type of trader is stabilizing as well as welfare improving for both consumers and society as a whole. If we think of increasing the number of spot traders, this is an expected result: these traders not only provide risk sharing but also impart a positive informational externality to secondary traders by making $P_{1}$ a better predictor of $P_{2}$.

It is perhaps slightly more surprising that increases in the number of uninformed traders are also beneficial since such increases in some sense lower the "average informedness" of market participants. However, this is mitigated by two factors: (1) the increase in risk sharing and (2) the fact that spot traders know all the actions of the uninformed secondary traders and so will tend to offset any mistakes they make. What matters is not average informedness but rather total inventory demand functions. The introduction of the secondary traders does not affect the quality of information held by the spot traders, and hence the spot traders' inventory demand function is unchanged.

\footnotetext{
${ }^{14}$ McCafferty and Driskill (1980) note the potential for nonexistence of equilibrium in a similar model in which prediction error variance is simultaneously determined.
} 
Adding the secondary traders thus makes the aggregate inventory demand function more elastic, which leads to price stability. The key to this reasoning lies in the fact that uninformed traders do not inflict any negative informational externality on the informed traders: spot traders retain perfect information throughout. When this feature disappears from the model, as it will under the more general information structure of subsection $C$, our conclusions can be reversed.

\section{Secondary Traders Observe Noisy Signal of A}

Here we will examine the intermediate case in which $v_{W}$ is neither zero nor infinite. In many ways, this case is more general and realistic than the first two. People often have access to some information other than what they can glean from prices. At the same time, it is unreasonable to assume that when they set out to learn something about an aggregate economic disturbance they can do a perfect job. First of all, people may make errors of judgment in interpreting news, statistics, and the like. While such errors might tend to "wash out" if every trader in a large group did his own research separately, this will not be true if large subgroups of traders get their information from common sources-if, for example, a significant number of traders all listen to E. F. Hutton or another big investment adviser. Second, even if people did do research independently, some components of the aggregate $A$ shock may simply be impossible to uncover directly. ${ }^{15}$

Even with the noise in the secondary traders' assessment of $A$, one might at first glance be tempted to conclude that they must be a stabilizing influence in this scenario if they were in the last. After all, average informedness seems to have risen. The spot traders can observe the same $X$ and $P_{1}$ as before, and the secondary traders are better informed in that they now have two channels of inference, $P_{1}$ and $Z$.

There are complications, however. Recall that, under the last scenario, spot traders could predict the actions of the secondary traders perfectly since the secondary traders' information was a subset of their own. This is what enabled them to infer $A$ exactly, given $P_{1}$ and $X$.

Now this breaks down. Since they do not know the nature of the secondary traders' measurement error $W$, the spot traders can no longer perfectly predict the inventory behavior of the secondary traders. Consequently, the spot traders cannot extract $A$ perfectly from

\footnotetext{
${ }^{15}$ The formulation used here leads to the same type of results as a model in which we write $A$ as the sum of two independent random variables and assume that one is directly observable while the other is not.
} 
their knowledge of $P_{1}$ and $X$. The REE pricing function for $P_{1}$ will now depend on $A, X$, and $W$ so that it is impossible to infer $A$ exactly knowing only $P_{1}$ and $X$.

This muddling of the spot traders' information has two effects: first, it raises their conditional variance on the second-period price, $V_{1}\left(P_{2}\right)$, since they are now unsure about more than the second-period transitory shock $Y$. As a result, $k_{1}$ falls, and spot traders are more reluctant to hold inventories than before. This is a destabilizing effect.

Second, for a given $k_{1}$, spot traders now make "mistakes" in their storage decisions that they did not make before. Again, this is destabilizing. Of course, these two negative effects are mitigated by the risk-sharing benefit that the incoming secondary traders confer. Still, the net effect may be destabilizing, as I will now attempt to show.

The addition of a third primitive random variable $(W)$ to the pricing function raises the dimensionality of the problem to a point where direct computation of the equilibrium for arbitrary values of $n_{1}$ and $n_{2}$ becomes an infeasible task. In order to skirt this difficulty, the model is specialized somewhat. From now on it is assumed that, when the secondary traders enter, they enter in very large numbers so that the group as a whole behaves in a risk-neutral fashion. As will become clear, this will allow a much more compact treatment of the problem without losing any of the basic spirit of the argument. As a second simplification, the variances of $A, X$, and $W$ will all be set to unity. This is done solely for notational economy and changes nothing essential. One variance that is not normalized in this way is $v_{y}$, the variance of the second-period transitory shock $Y$. For the purposes of the argument, it will be necessary to allow $v_{y}$, as well as $n_{1}$, to vary.

With three primitive random variables, the first-period price will have the following functional form:

$$
P_{1}=\alpha A+\beta X+\delta W,
$$

with $\alpha, \beta$, and $\delta$ left undetermined. This form leads to inventories and price changes given by

$$
\begin{gathered}
I=(\alpha+1) A+(\beta+1) X+\delta W, \\
P_{2}-P_{1}=-(2 \alpha+2) A-(2 \beta+1) X-2 \delta W-Y .
\end{gathered}
$$

Since secondary traders are risk neutral, it must be that, given their information, the expected price change is zero. This implies that $\operatorname{cov}\left[\left(P_{2}-P_{1}\right), Z\right]=0$ as well as that $\operatorname{cov}\left[\left(P_{2}-P_{1}\right), P_{1}\right]=0$. Given the expressions above as well as the assumptions of unit variance, these two requirements can be written as

$$
\begin{gathered}
-(2 \alpha+2)-2 \delta=0 ; \quad \text { or } \alpha=-1-\delta, \\
-\alpha(2 \alpha+2)-\beta(2 \beta+1)-2 \delta^{2}=0 .
\end{gathered}
$$


Spot traders, on the other hand, can expect some price change since they are not risk neutral. To compute their expectation requires "running a multiple regression" on their information of the form

$$
E_{1}\left(P_{2}-P_{1}\right)=b_{1} P_{1}+b_{2} X
$$

with the coefficients $b_{1}$ and $b_{2}$ being computed using the standard results from multivariate statistical theory. The algebra yields (after substitution for $P_{1}$ from [24])

$$
E_{1}\left(P_{2}-P_{1}\right)=\frac{(\alpha A+\delta W)\left[-\alpha(2 \alpha+2)-2 \delta^{2}\right]}{\alpha^{2}+\delta^{2}}-(2 \beta+1) X .
$$

Since we will be focusing on $k_{1}$ shortly, it is necessary to calculate the prediction error variance $V_{1}\left(P_{2}\right)$ that is crucial in determining it. This variance is given by

$$
V_{1}\left(P_{2}\right)=\frac{4 \delta^{2}}{\alpha^{2}+\delta^{2}}+v_{y}
$$

The interpretation is straightforward: when $\delta=0$, then the random variable $W$ does not enter into the pricing function. In such a case, $A$ can be inferred exactly from $P_{1}$ and $X$ so that the only source of prediction error is the second-period transitory shock $Y$. However, when $\delta$ is nonzero, there is the "muddling" effect mentioned earlier. Consequently, the prediction error variance increases beyond its full information value of $v_{y}$.

We are now almost ready to write down the remaining equilibrium conditions - those that correspond to forcing inventories as given by (25) to equal inventory demand. Spot trader inventory demand will be given by $k_{1}$ times the expected price change in (30). As for secondary trader demand, it will not be zero, even though their expectation of price change is zero. This is because there are an infinite number of secondary traders so that total demand can be a nonzero, finite number. For the purposes of finding the equilibrium, it is enough simply to express this limiting demand as a function of secondary trader information:

$$
D_{2}=C_{1} P_{1}+C_{2} Z=\left(\alpha C_{1}+C_{2}\right) A+\left(\delta C_{1}+C_{2}\right) W+\beta C_{1} X,
$$

where $D_{2}$ is secondary trader demand and $C_{1}$ and $C_{2}$ are temporarily undetermined finite numbers.

Equating inventory demand to inventories results in three equations, one each for the $A, W$, and $X$ components of inventories: 


$$
\begin{gathered}
C_{1} \alpha+C_{2}+\frac{k_{1} \alpha\left[-\alpha(2 \alpha+2)-2 \delta^{2}\right]}{\alpha^{2}+\delta^{2}}=\alpha+1, \\
C_{1} \delta+C_{2}+\frac{k_{1} \delta\left[-\alpha(2 \alpha+2)-2 \delta^{2}\right]}{\alpha^{2}+\delta^{2}}=\delta, \\
C_{1} \beta-k_{1}(2 \beta+1)=\beta+1 .
\end{gathered}
$$

These three equations, taken together with (27), (28), and (31), give us six equations that together determine the six unknowns $\alpha, \beta, \delta, C_{1}$, $C_{2}$, and $k_{1}$. No attempt is made here to solve them in a fully general case, although the Appendix does verify that an equilibrium does exist in general. Instead, an example is constructed to show how destabilizing speculation can occur.

\section{An Example of Destabilizing Speculation}

The first step in the example is to compute the equilibrium in the special case in which we ignore equation (31) and simply set $k_{1}$ to zero-an equilibrium with only the risk-neutral group of secondary traders participating. It is straightforward to show that in such a case

$$
\begin{gathered}
\alpha=-\frac{5}{6} ; \quad \beta=-\frac{4}{6} ; \quad \delta=-\frac{1}{6}, \\
\operatorname{var}\left(P_{2}-P_{1}\right)=\frac{1}{3}+v_{y} .
\end{gathered}
$$

As would be expected, the $\alpha=-1, \beta=-1 / 2, \delta=0$ ideal is impossible even with risk-neutral secondary traders since their information is imperfect.

The next step consists in choosing values of $n_{1}$ and $v_{y}$ that will illustrate the phenomenon of destabilization as clearly as possible. Let us assume that the number of spot traders $n_{1}$ is "very small"-not zero but arbitrarily close. Let us further write the variance of the secondperiod transitory shock, $v_{y}$, as $n_{1} / M$, where $M$ is some finite number, and assume that the risk-aversion coefficient $B$ is one. In the absence of a futures market, we would thus be in scenario $A$ of this section, with $k_{1}=M$. According to equation (19), price variability is equal to

$$
\text { spot } \operatorname{var}\left(P_{2}-P_{1}\right)=\frac{1}{(1+2 M)^{2}}+v_{y} .
$$

If $M$ is relatively large, the spot market comes very close to being a "perfect" regime: prices are almost totally stabilized, and speculative profits are nearly eliminated-the optimum situation from the point of view of both consumers and society as a whole. In fact, some simple 
calculations show that when $M \geq 3$, both welfare criteria deem the spot market regime above to be preferable to the all-secondary trader regime of (36) and (37).

What happens when a futures market is opened? The secondary traders enter, and we must now consider the more complicated equilibrium concept. Given the assumption of a "small" $n_{1}$ and $v_{y}$, the following proposition applies.

Proposition 2. The equilibrium with a futures market is "very close" to the all-secondary trader equilibrium of (36) and (37). Specifically, by choosing the appropriately small value of $n_{1}$, we can construct a futures market equilibrium that is arbitrarily close to that with only secondary traders.

To prove the proposition, first note that $k_{1}$ is always less than or equal to $M$. This implies that $\delta$ is nonzero since $\delta=0$ can satisfy the equilibrium conditions only if $k_{1}=\infty$. With a nonzero $\delta$, (31) tells us that $k_{1}$ can be made arbitrarily small by picking a small enough value of $n_{1}$. Since the all-secondary trader equilibrium - given by (27), (28), (33), (34), and (35) -is differentiable about $k_{1}=0$, it must be that, by setting $k_{1}$ small enough, we can come as close to this equilibrium as we wish.

The intuition is that as long as $k_{1}$ is not initially infinite, spot traders do not arbitrage the market perfectly. Consequently, secondary traders must enter, bringing their information with them and causing $W$ to enter the pricing function with nonzero weight $\delta$. With $n_{1}$ and $v_{y}$ both very small, the introduction of any additional uncertainty (reflected in the nonzero $\delta$ ) has a devastating effect on $k_{1}$ : it lowers it from a finite value of $M$ almost to zero. In this case, the misinformation that accompanies the influx of the secondary traders drives the small group of risk-averse spot traders almost completely out of the market, resulting in a new equilibrium that is very close to what would obtain if the secondary traders were in the market all alone. ${ }^{16}$

One caveat pertains, however. There is a "discontinuity" in the limit as $v_{y}$ approaches zero. While the logic above applies with both $n_{1}$ and $v_{y}$ small but nonzero, things change if $v_{y}$ equals zero exactly, with $n_{1}$ still positive. Now there can be two equilibria.

In the absence of futures markets, there is no uncertainty as to the second-period price, so even with a small $n_{1}, k_{1}$ is infinite and perfect stability is achieved. Consider what happens when a futures market is opened. One possibility is that the secondary traders never do any trading. This situation is self-sustaining because, as long as they stay

\footnotetext{
${ }^{16}$ The spot traders do not disappear from the point of view of inventory activity; they still perform storage. However, they now take negligibly small unhedged positions, and hence their private information is almost completely withdrawn from the market.
} 
out, there is no $W$ uncertainty, so $k_{1}$ remains infinite and prices are perfectly stable. With perfectly stable prices, there is no incentive for secondary traders to enter. They foresee no opportunities for profits. (With $\alpha=-1, \beta=-1 / 2, \delta=0, k_{1}=\infty$, along with $C_{1}=C_{2}=0$-no secondary trader activity - we satisfy the six equations.)

However, it is also possible to have an equilibrium in which the secondary traders are active. In such a case, there is uncertainty for the spot traders, so $k_{1}$ falls to almost zero. Consequently, spot traders alone no longer stabilize prices perfectly, thereby creating profit opportunities that justify the participation of the secondary traders.

Of these two equilibria, only the latter is a limit of the equilibria where $v_{y}$ is small but nonzero. As soon as we make $v_{y}$ a tiny bit positive, the spot traders do not perfectly stabilize the market by themselves because of the residual risk they face. As a result, secondary traders will always see some profit opportunities when a futures market is opened and will always trade actively. The other equilibrium arises only because of the discontinuity in $k_{1}$ that occurs when $v_{y}=0$, and there are no other sources of uncertainty; $k_{1}$ jumps to infinity then.

One interesting aspect of the "misinformation effect" described above is that it suggests that secondary traders as a group may be made better off with worse information. This cannot strictly be seen in the numerical example above because the risk neutrality of the secondary traders forced their profits to zero. But let us suppose instead that they are not quite risk neutral and that we are in the $v_{y}=0$ situation described above.

If the secondary traders could observe $A$ perfectly, we would be back to the results of subsection $A$. The only possible equilibrium is one of perfectly stable prices, with nobody making any profits. If, however, the secondary traders have a noisy observation of $A$, they can bring about the destabilizing equilibrium, in which they earn some profits (as long as they are not totally risk neutral). The worse information makes them better off because there is a benefit to being unpredictable. If spot traders can predict exactly what secondary traders will do, the market is riskless to the spot traders and they arbitrage away any potential profits. If, on the other hand, the actions of the secondary traders are unpredictable, the increased risk makes the risk-averse spot traders back out of the market somewhat, leaving behind imperfectly stabilized prices and the accompanying profit opportunities.

\section{Summary and Conclusions}

In addition to providing increased risk sharing, new speculators also bring new information to bear on the prices in the markets in which 
they operate. In general, informational externalities can be either positive or negative: the price can become more or less informative to those traders already in the market. When the externality is negative and strong in magnitude relative to the need for increased risk sharing (as it was in the specially constructed example in the previous section), the overall effect can be one of destabilization and welfare reduction.

The model has not relied on any irrationality on the part of speculators but rather on imperfections in their information. This is not an unreasonable approach, particularly in light of the fact that imperfectly informed speculators as a group may do as well as or better than perfectly informed ones. It is not necessarily true that imperfectly informed speculators will lose money to better informed ones and thus be driven out of business.

From the point of view of social welfare, one might say that "a little information is a dangerous thing." With extreme values of $v_{W}$, corresponding to either perfectly informed secondary traders $\left(v_{W}=0\right)$ or completely uninformed secondary traders $\left(v_{W}=\infty\right)$, there are no informational externalities. It is only in the intermediate range, with partially informed secondary traders, that problems can arise. The following unproven conjecture is offered: of all possible values of $v_{W}$, the one that minimizes social welfare will be approximately the same in magnitude as $v_{a}$. If $v_{W}$ is tiny relative to $v_{a}$, the noise cannot do much damage, no matter how much weight traders put on $Z$. If, on the other hand, $v_{W}$ is huge compared to $v_{a}$, optimizing traders will put a very small weight on their imprecise datum $Z$, so again the noise does little harm.

The notion that prices aggregate heterogeneous information is certainly not a new one. However, previous models of this phenomenon have not usually concerned themselves with the question of intertemporal price stability. Conversely, papers addressing the price stability and welfare effects of speculation have for the most part failed to pay sufficient attention to the informational aspects of speculative activity. This paper has attempted to bring together the techniques and insights of both strands of literature in order to suggest that both risksharing considerations and potentially adverse informational externalities must be taken into account when attempting to weigh the pros and cons of opening futures or options markets or of other measures designed to facilitate speculative behavior.

\section{Appendix}

\section{Derivation of (2) and (3)}

Consumers maximize equation (1) subject to the budget constraint $N=T-$ $\left(P_{1} C_{1}+P_{2} C_{2}\right)$, where $T$ is total endowment in terms of the numeraire good 
(i.e., giving up one unit of $C_{1}$ allows them to consume $P_{1}$ more units of $N$ ). The first-order conditions lead to the demand curves in the text. Note that these demands are independent of wealth or of the correlation between $P_{1}$ and $P_{2}$.

\section{Derivation of (6)}

Each inventory holder seeks to maximize $-e^{-B \pi}$, which, given the normality assumptions, is equivalent to maximizing $E(\Pi)-(B / 2) \operatorname{var}(\Pi)$. End-of-period profit is given by $\Pi=I\left(P_{2}-P_{1}\right)$. Thus the problem is

$$
\max I\left(E_{1} P_{2}-P_{1}\right)-\frac{1}{2} B I^{2} V_{1}\left(P_{2}\right) \text {. }
$$

The first-order condition is $I=\left(E_{1} P_{2}-P_{1}\right) /\left[B V_{1}\left(P_{2}\right)\right]$. Multiplying this inventory demand by $n_{1}$, the number of inventory holders, yields the result in the text. The derivation of (8) follows exactly the same logic.

\section{Derivation of (7)}

With futures trading, spot trader profit is now given by $\Pi=I\left(P_{2}-P_{1}\right)+$ $F_{1}\left(P_{2}-P_{f}\right)$. There is an additional source of potential gains to the extent that the price next period exceeds the futures price locked in today. The problem is thus

$$
\max I\left(E_{1} P_{2}-P_{1}\right)+F_{1}\left(P_{2}-P_{1}\right)-\frac{1}{2} B\left(I+F_{1}\right)^{2} V_{1}\left(P_{2}\right) .
$$

The first-order conditions with respect to $F_{1}$ yield the result in the text.

\section{Proof That Welfare Is Increasing in $\mathrm{k}_{1}$ in Section III $\mathrm{A}$}

Speculative profits $\Pi=I\left(P_{2}-P_{1}\right)=\left[k_{1} X /\left(1+2 k_{1}\right)\right]\left\{-Y+\left[X /\left(1+2 k_{1}\right)\right]\right\}$. So expected profits equal $E \Pi=v_{x} k_{1} /\left(1+2 k_{1}\right)^{2}$. Substituting into (9), we find that consumer welfare is given by

$$
U^{C}=-v_{a}-\frac{v_{y}}{2}-\frac{v_{x}\left(1+2 k_{1}^{2}+4 k_{1}\right)}{2+8 k_{1}^{2}+8 k_{1}},
$$

which is monotonically increasing in $k_{1}$.

To look at social welfare, we need to compute the expectation of the risk aversion term $\left(-B / 2 n_{1}\right) V_{1}\left(\Pi_{1}\right)$ in equation (11). This term can be rewritten as $\left(-B / 2 n_{1}\right) I^{2} V_{1}\left(P_{2}\right)$, which has expectation equal to $-v_{x} k_{1} /\left[2\left(1+k_{1}\right)^{2}\right]$. Substituting into (11), we find that social welfare is given by

$$
U^{s}=-v_{a}-\frac{v_{y}}{2}-\frac{v_{x}\left(1+2 k_{1}^{2}+3 k_{1}\right)}{2+8 k_{1}^{2}+8 k_{1}},
$$

which is monotonically increasing in $k_{1}$.

Similar arguments apply for the welfare assertions in Section IIIB.

\section{Proof That Prediction Error Variance Is Independent of $\alpha, \beta$ in Section III B}

Using the formulas in the text, we find that the prediction error $P_{2}-$ $E\left(P_{2} / P_{1}\right)$ is found to be

$$
\begin{aligned}
& A\left[-(2 \alpha+2)+\frac{\alpha^{2}(2 \alpha+2) v_{a}+\beta \alpha(2 \beta+1) v_{x}}{\alpha^{2} v_{a}+\beta^{2} v_{x}}\right] \\
+ & X\left[-(2 \beta+1)+\frac{\beta \alpha(2 \alpha+2) v_{a}+\beta^{2}(2 \beta+1) v_{x}}{\alpha^{2} v_{a}+\beta^{2} v_{x}}\right] .
\end{aligned}
$$




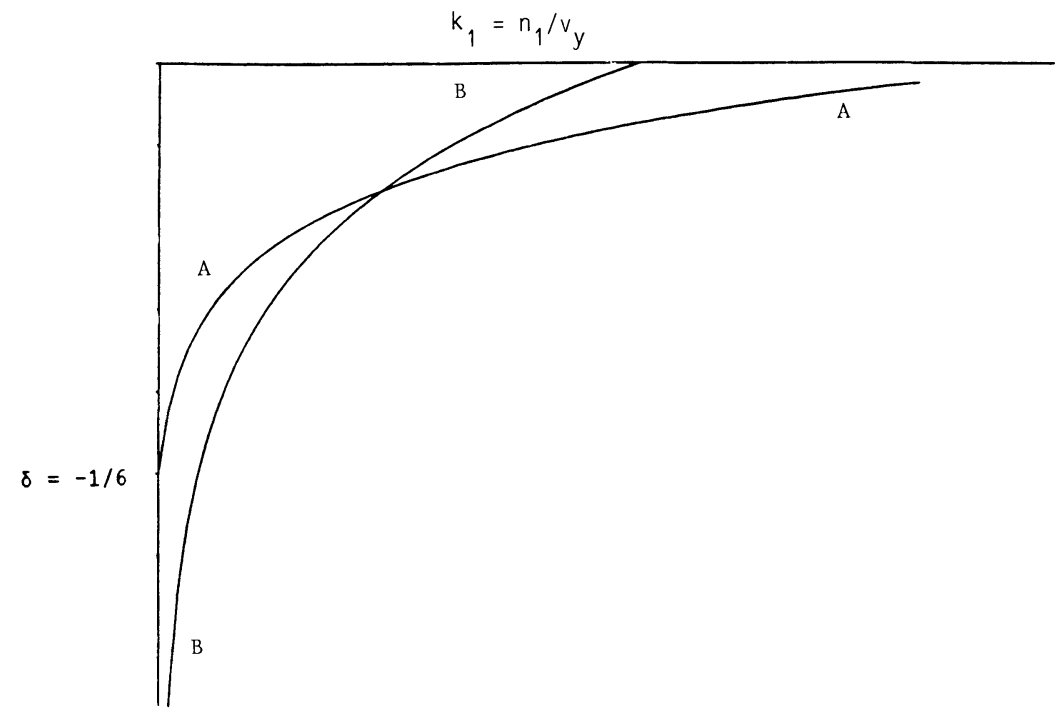

FIG. A1.-Existence of equilibrium in Sec. IIIC

In subsection $B$, we had $\beta=K \alpha$, with $K=\left(1+k_{1}\right) /\left(1+2 k_{1}\right)$. This simplifies the prediction error to

$$
\frac{A v_{x}\left(-2 K^{2}+K\right)}{v_{a}+K^{2} v_{x}}+\frac{X v_{a}(-1+2 K)}{v_{a}+K^{2} v_{x}},
$$

which is independent of $\alpha$. It does, however, depend on $K$, which in turn depends on the number of informed traders in the market. So we have a recursive structure: $k_{1}$ determines $k_{2}$ through the variance $V_{2}\left(P_{2}\right)$ (which, from the expression above, can be shown to be decreasing in $k_{1}$ ). Then $k_{1}$ and $k_{2}$ determine $\alpha$ and $\beta$.

\section{Proof That an Equilibrium Exists in Section IIIC}

Let us break our six-equation system down into two parts: The first part consists of the five equations (27), (28), and (33)-(35), a system where we can solve for $\alpha, \beta$, and $\delta$, taking $k_{1}$ as exogenous. It is straightforward to verify that this system has a unique solution for each value of $k_{1}$. Denote the locus of $\delta$ 's and $k_{1}$ 's that satisfy the five equations by $A A$. Along $A A, \delta$ is a continuous, monotonic function of $k_{1}$, moving from a value of $-1 / 6$ when $k_{1}=0$ to a value of zero when $k_{1}=\infty$.

The second part of the system consists of the equation that endogenizes $k_{1}$ as a function of $\delta-(31)$. (It is this endogeneity of prediction error variance that caused existence problems in McCafferty and Driskill [1980].) Denote the locus of $\delta$ 's and $k_{1}$ 's that satisfy (31) by $B B$. Along $B B, k_{1}$ is continuous in $\delta$, moving monotonically downward from its maximum value of $n_{1} / v_{y}$ at $\delta=0$.

Given these facts, it must be that the loci $A A$ and $B B$ intersect, as figure $A 1$ illustrates. Hence an equilibrium exists. 


\section{References}

Black, Fischer, and Scholes, Myron S. "The Pricing of Options and Corporate Liabilities." J.P.E. 81 (May/June 1973): 637-54.

Danthine, Jean-Pierre. "Information, Futures Prices, and Stabilizing Speculation.” J. Econ. Theory 17 (February 1978): 79-98.

Friedman, Milton. Essays in Positive Economics. Chicago: Univ. Chicago Press, 1953.

Grossman, Sanford J. "On the Efficiency of Competitive Stock Markets Where Traders Have Diverse Information.” J. Finance 31 (May 1976): 57385 .

. "The Existence of Futures Markets, Noisy Rational Expectations and Informational Externalities." Rev. Econ. Studies 44 (October 1977): 431-49.

$\rightarrow-$. "Further Results on the Informational Efficiency of Competitive Stock Markets." J. Econ. Theory 18 (June 1978): 81-101.

Grossman, Sanford J., and Stiglitz, Joseph E. "On the Impossibility of Informationally Efficient Markets.” A.E.R. 70 (June 1980): 393-408.

$\rightarrow$ Hart, Oliver D., and Kreps, David M. "Price Destabilizing Speculation." J.P.E. 94 (October 1986): 927-52.

$\rightarrow$ Hellwig, Martin F. "On the Aggregation of Information in Competitive Markets." J. Econ. Theory 22 (June 1980): 477-98.

McCafferty, Stephen, and Driskill, Robert. "Problems of Existence and Uniqueness in Nonlinear Rational Expectations Models." Econometrica 48 (July 1980): 1313-17.

Salant, Stephen W. "Profitable Speculation, Price Stability and Welfare." Mimeographed. Ann Arbor: Univ. Michigan, 1984.

$\rightarrow$ Samuelson, Paul A. "The Consumer Does Benefit from Feasible Price Stability." Q.J.E. 86 (August 1972): 476-93.

Turnovsky, Stephen J. "The Determination of Spot and Futures Prices with Storable Commodities.” Econometrica 51 (September 1983): 1363-87. 